\title{
Long term follow up of SHR rats with experimental yersinia associated arthritis
}

\author{
R Merilahti-Palo, C Gripenberg-Lerche, K-O Söderström, P Toivanen
}

\begin{abstract}
One hundred and one SHR rats were injected intravenously with live Yersinia enterocolitica 0:8. The rats were randomly divided into two groups consisting of 48 and 53 rats. The group of 48 rats was monitored for 245 days to establish the incidence and the clinical features of the arthritis. The remaining 53 rats were killed in groups of three to five rats at intervals from four to 245 days after inoculation to examine the clearance of bacteria and the development of histological changes in the synovial membrane.
\end{abstract}

Arthritis developed in $23 / 48(48 \%)$ rats at seven to 27 days after inoculation. The arthritis subsided in most rats within four weeks, without leading to ankylosis of the affected joints. The arthritis was prolonged in three rats and recurrent in two. In the group of 53 rats Yersinia enterocolitica 0:8 was cleared from most of the internal organs by day 77, but persisted in the inguinal lymph nodes in many of the rats up to day 245. All macroscopically arthritic joints showed clear histological signs of non-suppurative synovitis. No histological synovitis was detected in those joints observed macroscopically to be nonarthritic.

Yersinia associated arthritis in SHR rats provides a potential model for reactive arthritis. There are strong similarities in the course of the arthritis and histopathological changes in the synovium between this animal model and reactive arthritis in humans. This study supports the association between poor elimination of the causative agent and the development of arthritis.

Department of Medicine,

Turku University,

SF-20520 Turku,

Finland

R Merilahti-Palo

Department of

Medical Microbiology,

Turku University, SF-20520 Turku,

Finland

R Merilahti-Palo

C Gripenberg-Lerche

$P$ Toivanen

Department of

Pathology,

Turku University,

SF-20520 Turku,

Finland

K-O Söderström

Correspondence to:

Dr Riitta Merilahti-Palo,

Department of

Medical Microbiology,

Turku University,

Kiinamyllynkatu 13,

SF-20520 Turku,

Finland.

Accepted for publication

15 January 1991

Reactive arthritis caused by salmonella, shigella, yersinia, and campylobacter organisms provides a fascinating clinical model for studies of the pathogenesis of arthritis. Although many factors affecting reactive arthritis have been identified, questions about the pathogenesis of this disease still remain unresolved. For this reason, attempts have been made to create an appropriate animal model for reactive arthritis.

In 1973, Volkman and Collins described a chronic salmonella associated arthritis in adult (Lewis $\times \mathrm{BN} \mathrm{F}_{1}$ hybrid rats, in response to the intravenous injection of live Salmonella enteritidis. ${ }^{1}$ Bacteria were recovered from $40 \%$ of the rat joints tested within the first month after infection. The observation that intra-articularly injected Salmonella enteritidis did not induce chronic arthritis suggests that the arthritis was not only caused by the destructive properties of the bacteria in the joints. ${ }^{2}$ This early salmonella associated arthritis served as the original guideline for our attempts to create a rat model for yersinia induced arthritis.

In previous experiments, we infected five different rat strains (Lewis, Wistar, Zucker, WKY and SHR) intravenously with live Yersinia enterocolitica O:8 and Yersinia pseudotuberculosis III. ${ }^{3}$ The serotype 0:8 Yersinia enterocolitica strain was earlier shown by Carter et al to be lethal to mice. ${ }^{4}$ At doses of $10^{5}$ and $10^{6}$ Yersinia enterocolitica O:8 bacteria, five of 12 (42\%) SHR rats developed arthritis. ${ }^{3}$ The other yersinia inoculated rat strains did not develop arthritis. Susceptibility to arthritis seemed to be related to susceptibility to infection, the SHR rats being more prone than the Lewis, Wistar or Zucker rats to death as a result of infection. ${ }^{3}$

Hill and Yu described arthritis in Lewis rats after intravenous injection with Yersinia enterocolitica $0: 8 .^{5}$ The other rat strains tested (Buffalo, Fisher, DA and LDA) did not develop arthritis. In their experiments, systemic infection persisted for a significantly longer time in the arthritis susceptible Lewis rats than in the arthritis resistant strains. ${ }^{5-7}$ Thus the development of yersinia associated arthritis in rats involves at least the following critical features: genetic susceptibility of the hosts, bacterial strain specificity, and bacterial dose dependency.

This report gives a detailed description of the incidence, long term clinical features, bacterial clearance, and development of histological changes in the synovium in experimental yersinia associated arthritis in SHR rats. A preliminary report has been published elsewhere. ${ }^{8}$

\section{Materials and methods}

\section{EXPERIMENTAL DESIGN}

A total of 101 SHR rats were studied. They were injected intravenously with live Yersinia enterocolitica 0:8 and were randomly divided into two groups.

One group, consisting of $\mathbf{4 8}$ rats, was followed up for 245 days to establish the incidence and clinical features of the induced arthritis. The other group, consisting of 53 rats, was killed in groups of three to five rats on days $4,8,14,21$, $28,35,49,77,108,133$, and 175 . On day 245 , eight rats were killed. In the second group, the clearance of Yersinia enterocolitica 0:8 from different organs was assessed. Synovial samples were studied from 47 of these 53 rats to establish the histological course of the arthritis. We tried to include, at each time, both arthritic and non-arthritic rats for the clearance and histological studies. 
EXPERIMENTAL ANIMALS

Adult male (240-300 g) and female (170-200 g) specific pathogen free SHR rats from Mollegaard Ltd (Skensved, Denmark) were used. These rats were negative for all bacteria, mycoplasma, and viruses tested, except Bacillus piliformis. They appeared to be healthy and free of any clinical symptoms. They were conventionally maintained on a standard diet and given tap water freely. The rats were kept in Macrolon III cages, three to four animals in each, on autoclaved aspen wood bedding.

\section{YERSINAE}

The Yersinia enterocolitica O:8 WA strain, originally from Dr P Gemski (Washington DC), was obtained from DrT Nurmi(Oulu University, Oulu; Finland). The strain is virulence plasmid and autoagglutination positive. ${ }^{9}$ The bacteria were stored at $-70^{\circ} \mathrm{C}$ in Tryptone Soya Broth (Oxoid, Basingstoke, UK) containing 20\% glycerol and were subsequently recovered by culture on lactose agar for two days at room temperature. To select for virulent organisms, the bacterial dose was adjusted to $3 \times 10^{5}$ bacteria $/ \mathrm{ml}$ in $0.9 \%$ sodium chloride, using McFarland turbidity standards, and injected intravenously into $\mathrm{BALB} / \mathrm{cA}$ mice $(0.5 \mathrm{ml} /$ mouse). One day later the mice were killed and the spleen cultured on lactose agar. Recovery of Yersinia enterocolitica 0:8 was confirmed by slide agglutination using specific rabbit antisera to different serotypes of Yersinia enterocolitica. The presence of the plasmid was confirmed by autoagglutination. These virulent bacteria were subcultured overnight in Brain Heart Infusion (Difco, Detroit, MI, USA) tubes. The bacteria were then inoculated into fresh Brain Heart Infusion (1:20), cultured on a shaker at room temperature to an absorbance of 0.3 , and finally diluted in appropriate concentrations in $0.9 \%$ sodium chloride solution using McFarland turbidity standards. The concentration of viable bacterial cells was further estimated by the most probable number method. ${ }^{10}$

\section{INTRAVENOUS INFECTION}

The rats were given a single dose into a tail vein of either $10^{5}$ or $10^{6}$ live Yersinia enterocolitica $0: 8$ bacteria in $1.0 \mathrm{ml} 0.9 \%$ sodium chloride solution.

\section{ESTIMATION OF ARTHRITIS}

Each limb was examined every two days for the first month and thereafter twice a week for up to 245 days. The arthritis was scored in each limb as follows: 0 indicates no detectable swelling; 1 , overt swelling, but contours of the joint maintained; 2, swelling with obliteration of contours; and 3, gross distortion of the joint. The estimation of arthritis was performed independently by two observers.

The arthritic score for each rat was calculated by dividing the sum of the limb scores by four. (from arthritic joints), liver, spleen, lungs, heart, kidneys, and blood (by heart puncture) were taken using sterile methods. The samples were cultured by direct plating on lactose agar and cefsulodin-irgasan-novobiosin agar (Oxoid) and by plating after enrichment for one and three weeks at $4^{\circ} \mathrm{C}$ in yeast extract-rose bengal broth, as described by Schiemann. ${ }^{11}$ Suspected Yersinia enterocolitica O:8 colonies were identified with API-20E strips (API System, Montalieu, France) and by slide agglutination with specific rabbit antisera to Yersinia enterocolitica O:8. Antisera against other yersiniae were used as negative controls.

\section{HISTOLOGY}

Joint, heart, and kidney specimens were taken from arthritic and non-arthritic rats for microscopic studies. To prepare the joint specimens, the skin was thoroughly wetted with $96 \%$ denatured alcohol, divided by a long vertical incision and removed. The ankle joints were removed by sectioning the tibia and fibula proximally and the metatarsal bones distally.

The specimens were fixed in $4 \%$ neutral buffered formaldehyde and the joint specimens were decalcified for six to seven hours in $14 \%$ hydrochloric acid (New-Calc, Algol, Helsinki, Finland). All specimens were then dehydrated, embedded in paraffin, cut into $5 \mu \mathrm{m}$ thick sections and stained with the van Gieson and haematoxylin-eosin stains. The ankle joints were cut longitudinally so that the surrounding tissues and bones were included in the same joint section.

The microscope observations were made with a Leitz-Dialux 22 microscope and read blindly by one observer.

The amounts of lymphocytes, plasma cells, and polymorphonuclear leucocytes in the joint synovia were estimated. This was achieved by choosing a representative area, avoiding those areas containing the highest amount of inflammatory cells and estimating instead an area of average inflammation. The area evaluated consisted of the ocular rectangle, defining the area included in the microscopic photographs, and measuring about $0.5 \mathrm{~mm}^{2}$. The lymphocytes, polymorphonuclear leucocytes, and plasma cells were all counted in the same area.

The amount of fibrin on the synovia was estimated using a scale from 0 to 3 , where 0 indicated no fibrin, 1 small fibrin fragments, 2 half the synovia covered by fibrin, and 3 all synovia covered by fibrin. The extent of ulceration of the synovial lining mesothelia was estimated on a scale of $0-3$, where 0 indicated no ulceration, 1 small local ulcerations, 2 about half the synovia ulcerated and 3 all synovia ulcerated. The amount of fibrosis was estimated using a scale of $0-2$, where 0 indicated no fibrosis, 1 a clearly increased amount of fibrosis, and 2 massive fibrosis. The presence of haemosiderin in the synovia was also determined.

Erosion of the cartilage was estimated using a scale of $0-3$, where 0 indicated no erosion, 1 small areas of erosion, 2 about half of the cartilaginous surface eroded, and 3 all cartilaginous surface eroded. 
Vascular proliferation was estimated on a scale of $0-3$, where 0 indicated no proliferation, 1 a small increase in the number of vessels, 2 approximately $50 \%$ increase in blood vessels, and 3 greater than $50 \%$ increase in the number of blood vessels. The presence of vasculitis was also determined in the synovia.

The thickness of the mesothelial cells lining the synovia was also assessed: the number of cell layers on top of each other was determined in representative areas of the synovia.

The means and standard deviations were calculated in all instances.

The microscopic parameters were recorded blindly, with no knowledge of the bacterial culture outcome, of the time of killing of the rat after inoculation, nor of the clinical status of the joints.

\section{Results}

\section{OCCURRENCE AND COURSE OF ARTHRITIS}

This part of the experiment was designed to study the incidence and the long term clinical course of arthritis induced by Yersinia enterocolitica $0: 8$ in SHR rats. The 48 rats were followed up for 245 days. Half of the rats were injected intravenously with $10^{5}$ and the other half with $10^{6}$ live Yersinia enterocolitica 0:8. Of the total of 48 rats, $23(48 \%)$ developed clinical arthritis. Table 1 shows that there was no significant difference in the incidence of arthritis based on bacterial dose or sex of the rats. ${ }^{9}$ The two dose groups were therefore combined in further analysis.

The arthritis was preceded by weight loss, ruffling of the fur, and tenderness of the legs on movement. The arthritis appeared as erythema, followed by gradually worsening swelling and impaired movement of the joint. The mean starting day of arthritis was day 14 after inoculation (range 7-27 days). Figure 1 shows

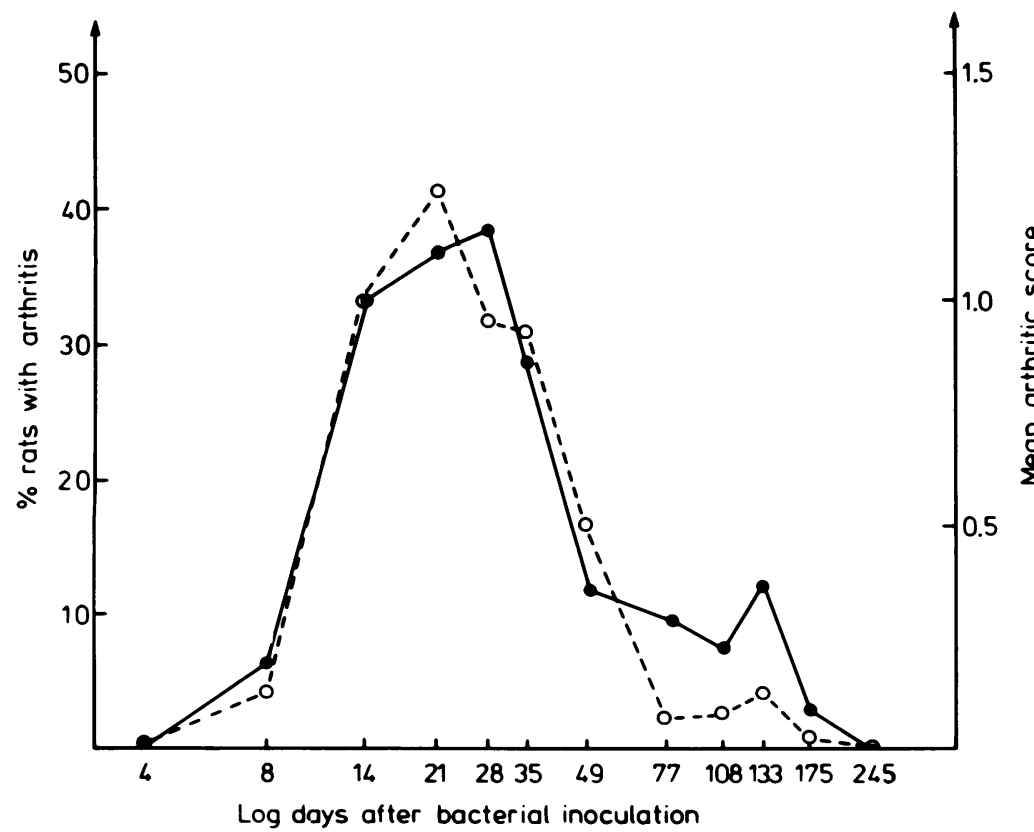

Figure 1 Occurrence of arthritis in 48 SHR rats after intravenous inoculation with Yersinia


in the total group at each time. (See under Materials and methods for definition of mean arthritic score.)
Table 1 Incidence of arthritis associated with Yersinia enterocolitica O:8 in SHR rats. Forty eight SHR rats were inoculated intravenously with Yersinia enterocolitica $O: 8$ and observed for arthritis for 245 days

\begin{tabular}{lll}
\hline Sex & $\begin{array}{l}\text { Bacterial } \\
\text { dose }\end{array}$ & $\begin{array}{l}\text { Number of rats } \\
\text { with arthritis/total } \\
\text { number of rats }(\%)\end{array}$ \\
\hline Male & $10^{5}$ & $5 / 12(42)$ \\
Female & $10^{6}$ & $7 / 11(64)$ \\
& $10^{5}$ & $6 / 12(50)$ \\
\hline
\end{tabular}

the peak of the arthritis occurring on days 14-28 after bacterial inoculation, subsiding thereafter. Altogether, 48 joints of the 23 arthritic rats were macroscopically arthritic. The arthritis was most common in the ankle joints (42/48), with marked swelling around the Achilles tendon. In 4/23 arthritic rats the arthritis affected only one paw, in 13/23 two paws, and in 6/23 three paws. In no rats were all four limbs affected. The mean duration of arthritis was 21 days (range 7-32 days).

Most of the rats recovered from arthritis symptoms by day 49 . However, in five rats the disease differed. In three of the five rats, arthritis persisted for several months. One of these three arthritic rats died 20 weeks after inoculation. One appeared to be completely cured after five months of arthritis. In the third rat, seven months of arthritis led to ankylosis of the joint.

In the two remaining rats the arthritis recurred after a non-arthritis period of five and 11 weeks. The first of these two rats developed arthritis of both hind paws 13 days after inoculation. The arthritis subsided by week 14 . A spontaneous flare was detected in the left hind paw at week 25 , with less severe symptoms than the first episode. The arthritis lasted for one week. In the second rat, primary arthritis of both hind paws began at day 13 and subsided at day 35 after inoculation. A spontaneous flare up was noted in the right hind paw at week 10, subsiding within two weeks. At week 14 a third flare was observed in the same joint two weeks after recovery from the second phase of arthritis. As with the first rat, these two flares were less severe than the primary arthritis. Both rats had apparently normal joints with full movement when killed on day 245 . Both rats with recurrent arthritis were male, inoculated with a dose of $10^{6}$ bacteria. Two of the rats with persistent arthritis were male; one had been inoculated with $10^{5}$ bacteria and the other with $10^{6}$. One female rat, inoculated with $10^{5}$ bacteria, developed persistent arthritis which subsided after five months.

During the follow up period nine rats died. The deaths occurred on days 20 (2), 21, 22, 29, $31,32,77$, and 140 . Three of these rats had received $10^{5}$ yersinia organisms and the other six rats received $10^{6}$. All nine were arthritic. At necropsy they had gross signs of systemic infection with macroscopic abscesses in the liver, spleen, lungs, and kidneys. 
Table 2 Recovery of Yersinia enterocolitica O:8 from various organs of inoculated SHR rats. SHR rats $(n=51)$ were inoculated with Yersinia enterocolitica $O: 8$. At the indicated time, rats were killed and their organs were cultured for the recovery of Yersinia enterocolitica $O: 8$. The results indicate the number of Yersinia enterocolitica $O: 8$ positive cultures detected

\begin{tabular}{|c|c|c|c|c|c|c|c|c|c|c|c|c|}
\hline \multirow[t]{2}{*}{ Organ } & \multicolumn{12}{|c|}{ No of days after inoculation } \\
\hline & 4 & 8 & 14 & 21 & 28 & 35 & 49 & 77 & 108 & 133 & 175 & 245 \\
\hline $\begin{array}{l}\text { Joint* } \\
\text { Joint fluid } \\
\text { Blood } \\
\text { Heart } \\
\text { Lung } \\
\text { Liver } \\
\text { Kidney } \\
\text { Spleen } \\
\text { Faeces } \\
\text { Inguinal lymph nodes }\end{array}$ & $\begin{array}{l}0 \\
\text { ND } \\
1 \\
1 \\
1 \\
3 \\
1 \\
2 \\
4 \\
\text { ND }\end{array}$ & $\begin{array}{l}0 \\
0 \\
0 \\
0 \\
4 \\
3 \\
1 \\
3 \\
4 \\
\text { ND }\end{array}$ & $\begin{array}{l}1 \\
0 \\
0 \\
0 \\
3 \\
3 \\
2 \\
3 \\
4 \\
\text { ND }\end{array}$ & $\begin{array}{l}1 \\
0 \\
1 \\
1 \\
4 \\
4 \\
2 \\
3 \\
5 \\
\text { ND }\end{array}$ & $\begin{array}{l}0 \\
0 \\
0 \\
0 \\
1 \\
1 \\
0 \\
1 \\
4 \\
\text { ND }\end{array}$ & $\begin{array}{l}0 \\
0 \\
1 \\
1 \\
2 \\
2 \\
1 \\
2 \\
4 \\
\text { ND }\end{array}$ & $\begin{array}{l}0 \\
\text { ND } \\
0 \\
0 \\
0 \\
0 \\
0 \\
0 \\
0 \\
\text { ND }\end{array}$ & $\begin{array}{l}0 \\
\text { ND } \\
0 \\
0 \\
0 \\
1 \\
1 \\
1 \\
1 \\
\text { ND }\end{array}$ & $\begin{array}{l}0 \\
\text { ND } \\
0 \\
0 \\
0 \\
0 \\
0 \\
0 \\
0 \\
1\end{array}$ & $\begin{array}{l}0 \\
\text { ND } \\
0 \\
0 \\
0 \\
0 \\
0 \\
0 \\
0 \\
1\end{array}$ & $\begin{array}{l}0 \\
\text { ND } \\
0 \\
0 \\
0 \\
0 \\
0 \\
0 \\
2 \\
1\end{array}$ & $\begin{array}{l}0 \\
\mathrm{ND} \\
0 \\
1 \\
1 \\
1 \\
1 \\
1 \\
2 \\
6\end{array}$ \\
\hline Number of rats studied & 4 & 4 & 4 & 5 & 4 & 4 & 3 & 4 & 4 & 4 & 3 & 8 \\
\hline
\end{tabular}

*Ankle joints.

ND $=$ not determined.

venously with $10^{5}$ or $10^{6}$ live Yersinia enterocolitica $0: 8$ at the same time. The incidence of arthritis in this group was $28 / 53(53 \%)$. Two rats died spontaneously during the study, disallowing subsequent bacterial cultures from these rats. On days $4,8,14,21,28,35,49,77$, $108,133,175$, and 245 after bacterial inoculation, 51 rats were killed in groups of three to five rats. Necropsies were performed on the rats and samples were taken from the synovium, synovial fluid, blood, heart, lungs, liver, kidneys, spleen, faeces, and, in some rats, the inguinal lymph nodes.

Macroscopic abscesses were frequently seen in the liver, spleen, kidneys, and lungs between days 14 and 77 after bacterial inoculation. From day 108 to day 245, large abscesses in the inguinal lymph nodes became obvious in 11/19 rats. At this time, abscesses were rarely seen in the other internal organs. Yersinia enterocolitica $0: 8$ isolations correlated well with the occurrence of macroscopic abscesses. Excretion of Yersinia enterocolitica $0: 8$ in the faeces lasted, in all rats, up to day 35 , and up to day 245 in $2 / 8$ rats. In two rats, yersinia were recovered from the synovium at days 14 and 21 , respectively. In

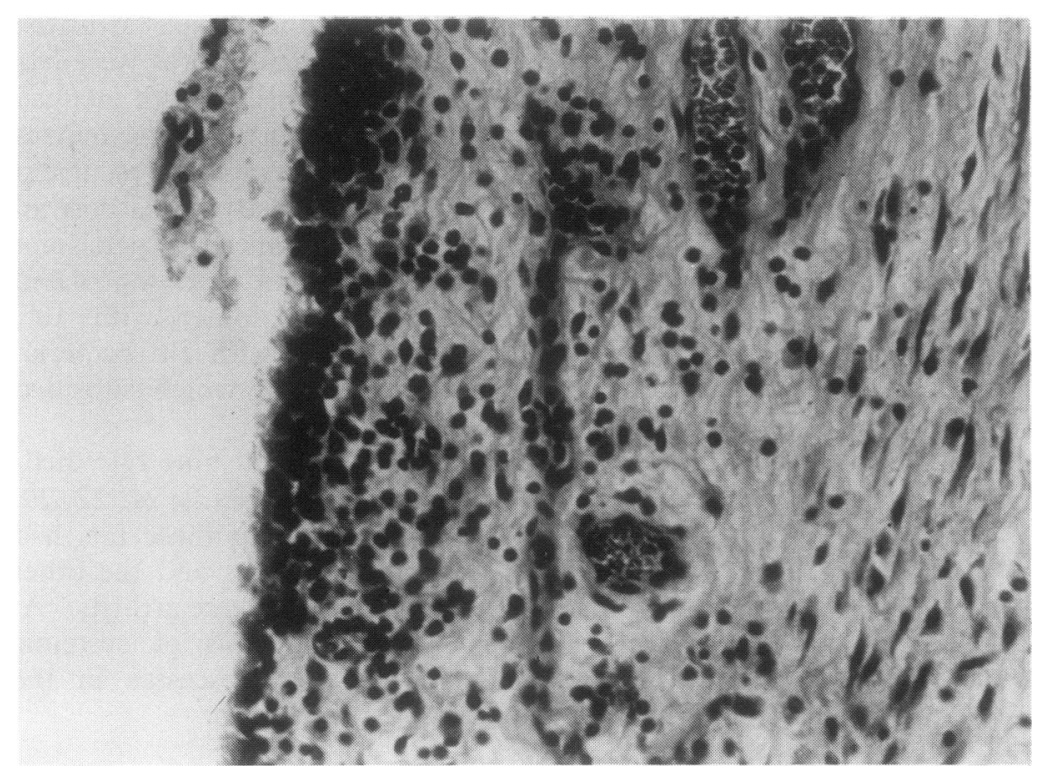

Figure 2 Biopsy specimen from the synovial membrane of an SHR rat 12 days after inoculation with Yersinia enterocolitica O:8. The mesothelial lining layer has proliferated and the subsynovium is infiltrated mainly by small lymphocytes. (Haematoxylin and eosin stain.) these two rats, the duration of macroscopic arthritis had been five and three days, respectively. Table 2 shows the results of the bacterial cultures.

Both rats with recurrent arthritis had large abscesses in the inguinal lymph nodes, from which live yersinia were recovered at the time of killing. Both rats with persistent arthritis also had abscesses either in the inguinal lymph nodes or kidneys at the time of death at week 20 or at the time of killing at day 245 . The rat with persistent arthritis subsiding after five months had no macroscopic abscesses and cultures of the internal organs and faeces were negative for yersinia growth.

\section{HISTOLOGICAL FINDINGS}

For the determination of histopathological changes during the course of the arthritis, joint samples from 47 of the 53 rats were taken at the time intervals indicated above. The joint samples were then grouped according to the duration of macroscopic arthritis, rather than the time after inoculation with bacteria. This was because the starting day of arthritis varied from seven to 27 days after inoculation. All macroscopically arthritic joints showed clear histological signs of synovitis. The strongest inflammatory changes occurred at three to 56 days after the start of macroscopic arthritis (fig 2). No histological synovitis was detected in the joints of those rats judged macroscopically to be non-arthritic.

Inflammatory cells were diffusely distributed in the oedematous synovia. At all stages of arthritis the predominant inflammatory cells were lymphocytes. No nodules or reaction centres were found. Polymorphonuclear leucocytes were only seen in early arthritis and their number was considerably less than that of the lymphocytes. The number of plasma cells was low. Table 3 shows that even after long periods after inoculation, no increase was seen in the plasma cell number.

The synovial lining cell layer was mildly thickened, consisting of two to four cell layers at all stages of arthritis. Mild changes of synovial ulceration were seen at six to 19 days after the start of arthritis. Mild fibrosis was seen 11 days after the start of arthritis. Erosion of the cartilaginous surface was seen from the fairly 
Table 3 Analysis of types of inflammatory cells in the synovium of SHR rats with arthritis. The inflammatory cells were counted in a representative $0.5 \mathrm{~mm}^{2}$ area of the synovium of the ankle joints of SHR rats injected intravenously with Yersinia enterocolitica $O: 8$

\begin{tabular}{|c|c|c|c|c|}
\hline \multirow{2}{*}{$\begin{array}{l}\text { Duration of } \\
\text { arthritis (days) }\end{array}$} & \multicolumn{3}{|c|}{ Number of cells (mean $(S D)$ ) } & \multirow{2}{*}{$\begin{array}{l}\text { Number of } \\
\text { rats studied }\end{array}$} \\
\hline & Polymorphonuclear & Mononuclear & Plasma cells & \\
\hline $\begin{array}{l}0 \\
3 \\
6-8 \\
11 \\
15-19 \\
26-56 \\
126-224 \\
\text { Cured }\end{array}$ & $\begin{array}{l}0 \\
0 \\
10(16) \\
1(4) \\
0 \\
0 \\
0 \\
0\end{array}$ & $\begin{array}{c}1(1) \\
26(6) \\
38(12) \\
23(13) \\
23(13) \\
21(28) \\
0 \\
0\end{array}$ & $\begin{array}{l}0 \\
3(1) \\
5(3) \\
1(1) \\
4(1) \\
3(2) \\
0 \\
0\end{array}$ & $\begin{array}{r}19 \\
2 \\
5 \\
2 \\
4 \\
4 \\
2 \\
9\end{array}$ \\
\hline
\end{tabular}

early stage of arthritis, but bony erosion was never seen, even at late stages of arthritis. Figure 3 shows that joints cured of arthritis appeared histologically normal. Mild vascular proliferation was seen only in more advanced arthritis. Table 4 gives the amounts of ulceration, fibrosis, erosion, and vascular proliferation in the synovia. No giant cells, accumulation of haemosiderin nor clear vasculitis were found in the synovia.

Simultaneously with the inflammatory reaction in the synovia, abscesses were seen in the kidneys, muscles, and bones. In addition, a pericarditis was also found in the hearts of three of four rats tested. These abscesses differed from synovial inflammation in that they contained solely polymorphonuclear leucocytes,

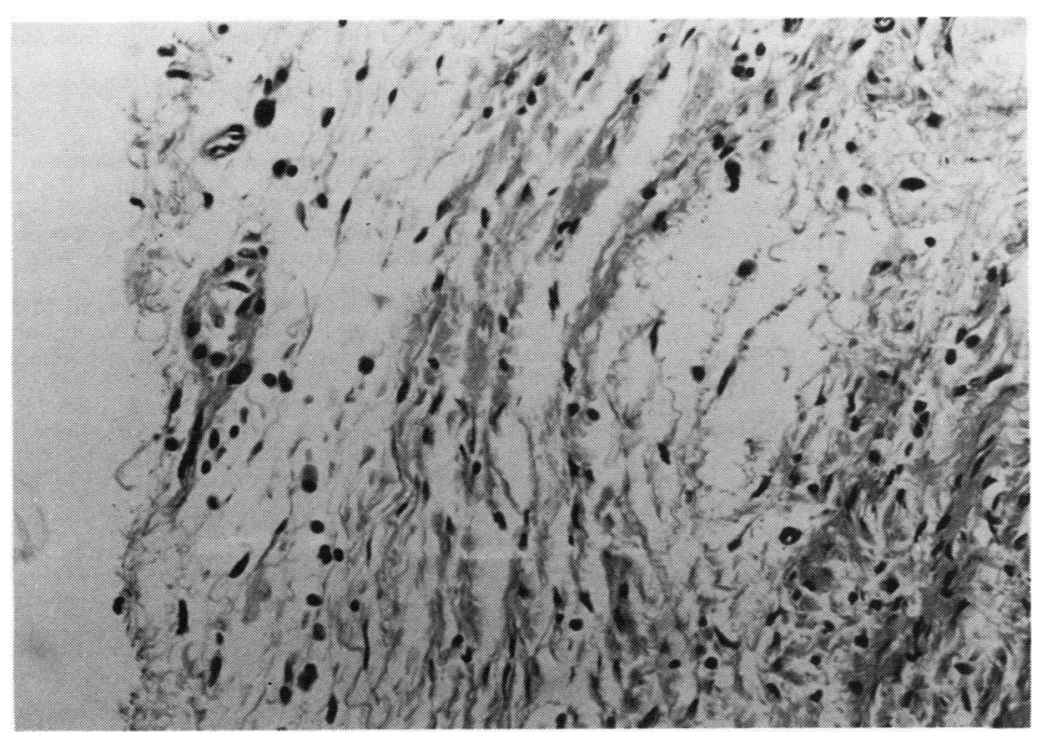

Figure 3 Biopsy specimen from the synovial membrane of an SHR rat 35 days after inoculation with Yersinia enterocolitica O:8. A few lymphocytes are still seen in the subsynovium. (Haematoxylin and eosin stain.) and not the lymphocytes seen in synovial inflammation. In addition, in both the pericarditis and in the abscesses, bacteria were seen in the gram staining. Bone abscesses were also seen, predominantly located in the middle of the bones. Such abscesses did not extend into the joints. No histological nephritis was detected in the kidneys of four rats randomly selected for examination.

\section{Discussion}

In a previous study we showed that SHR rats develop arthritis after intravenous inoculation of $10^{5}$ or $10^{6}$ Yersinia enterocolitica 0:8 organisms. ${ }^{3}$ Arthritis was seen in five of the $12(42 \%)$ rats tested until day 30 . The incidence of arthritis in this continued study is consistent with the earlier finding. The clinical features of the arthritis showed, in addition to the acute arthritis seen in the preliminary study, persisting and recurrent forms of the disease. In this respect the disease resembles the clinical course seen in streptococcal cell wall induced arthritis in rats. ${ }^{12} \mathrm{~A}$ major difference from streptococcal cell wall arthritis is that the acute arthritis in most rats did not lead to ankylosis of the affected joints. This is identical to the usually self limiting and non-erosive nature of human reactive arthritis. ${ }^{13}$

Murine respiratory mycoplasmosis is an important spontaneous disease of laboratory rats and mice. ${ }^{14}$ Mycoplasma pulmonis infection has been reported to have a suppressive effect on both adjuvant and collagen induced arthritis in rats. ${ }^{15}$ During our study, a few rats suffered from mild upper respiratory tract symptoms. IgG antibodies against Mycoplasma pulmonis (State Veterinary Institute, Uppsala, Sweden) were detected in 15 of 33 rats tested. The occurrence of such antibodies, however, is not correlated with the occurrence of arthritis. As evidence of mycoplasma infection became apparent long after inoculation, the effect of such co-infection cannot be determined. Whether or not the mycoplasma infection reduced the incidence of arthritis in this study cannot be excluded. The group of 51 rats killed at specified time intervals was also tested for IgG antibodies against Yersinia enterocolitica O:8. ${ }^{16}$ As expected, all the rats had significantly increased antibody titres from day 14 , reflecting the systemic Yersinia enterocolitica $0: 8$ infection. No difference between the arthritic and nonarthritic rats was seen in the occurrence of

Table 4 Histological changes in the synovium of SHR rats with arthritis. The amounts of ulceration of the lining cell layer, fibrosis of the subsynovium, erosion of cartilage, and vascular proliferation were estimated on a scale of $0-3$ (see under Materials and methods) in the synovium of SHR rats inoculated intravenously with Yersinia enterocolitica O:8

\begin{tabular}{|c|c|c|c|c|c|}
\hline \multirow{2}{*}{$\begin{array}{l}\text { Duration of } \\
\text { arthritis (days) }\end{array}$} & \multicolumn{4}{|c|}{ Amount of each histological change (mean $(S D)$ ) } & \multirow{2}{*}{$\begin{array}{l}\text { Number of } \\
\text { rats studied }\end{array}$} \\
\hline & Ulceration & Fibrosis & Erosion & $\begin{array}{l}\text { Vascular } \\
\text { proliferation }\end{array}$ & \\
\hline $\begin{array}{l}0 \\
3 \\
6-8 \\
11 \\
15-19 \\
26-56 \\
126-224 \\
\text { Cured }\end{array}$ & $\begin{array}{l}0 \\
0 \\
1 \\
1 \\
1 \\
1 \\
0 \\
0 \\
0\end{array}$ & $\begin{array}{ll}0 \\
0 \\
0 \\
1 & (1) \\
1 & (1) \\
1 & (1) \\
0 & \\
0 & \end{array}$ & $\begin{array}{l}0 \\
1 \\
2 \\
2 \\
1 \\
0 \\
0 \\
0\end{array}$ & $\begin{array}{l}0 \\
0 \\
0 \\
0 \\
1 \\
1 \\
1 \\
0 \\
0 \\
0\end{array}$ & $\begin{array}{r}19 \\
2 \\
5 \\
2 \\
4 \\
4 \\
2 \\
9\end{array}$ \\
\hline
\end{tabular}


antibodies against Mycoplasma pulmonis and Yersinia enterocolitica.

Susceptibility to arthritis in SHR rats in the previous study appeared to be related to susceptibility to infection. ${ }^{3}$ In this study, we showed that live Yersinia enterocolitica O:8 were recovered a fairly long time after inoculation in the SHR rats, especially in the inguinal lymph nodes, in most rats tested up to 245 days after inoculation. The bacteria were usually cleared from the other internal organs before day 108 after inoculation. In one rat, bacteria were recovered from the liver, spleen, kidney, heart, and lung at day 245 , but this rat also harboured yersinia in the lymph nodes. The infection may have persisted in the organs or, alternatively, may have been a consequence of new bacteria spread from the lymph nodes. The two rats with recurrent arthritis and two of the three rats with persisting arthritis harboured yersinia in their lymph nodes until the end of the study at day 245 . The one rat with five months of persisting arthritis had no signs of infection at day 245; the arthritis in this rat had resolved two months earlier. Prolonged arthritis also seems to be correlated with prolonged infection.

The histological changes correlated with the macroscopic changes observed in the rats. The red, swollen joints showed clear histological evidence of an acute synovitis. The inflammatory cells in all the arthritic rats consisted mainly of mononuclear cells; this is consistent with the arthritis being non-purulent. Two rats yielded positive cultures for Yersinia enterocolitica $0: 8$ in the synovia in early arthritis. This parallels the findings of Volkman and Collins for salmonella induced arthritis in the rat, ${ }^{1}$ and the findings in our previous study with yersinia induced arthritis in SHR rats. ${ }^{3}$ Thus it still seems that in at least some of the rats, the initial phase of the arthritis involves bacterial dissemination in the joint. $^{3}$ This has not been shown in yersinia reactive arthritis in humans, although the distinction between post-infectious and reactive arthritis has become blurred as a result of recent findings of bacterial antigens in human joints in reactive arthritis. ${ }^{17-22}$

In later stages, the histological results resembled a more chronic form of non-specific arthritis, with fibrosis and vascular proliferation. The histological changes included erosion of the cartilaginous surface in the early stages of arthritis, but it did not extend to the bone. Cardiac and renal involvement is occasionally seen in human reactive arthritis, ${ }^{13} 23$ but in this rat model there was no histological evidence for nephritis and, moreover, the pericarditis seen in some of the rats was clearly suppurative.

Based on the findings presented here, we conclude that yersinia associated arthritis in SHR rats provides a potential animal model for the study of reactive arthritis. The most striking similarities between this animal model and human reactive arthritis are the histopathological characteristics and the self limiting course of the disease in most of the rats. As has been proposed in reactive arthritis in humans, ${ }^{24}$ poor clearance of the initial infective agent is associated with susceptibility to arthritis in the rat model. The role of yersinia antigens, their persistence and the role of $T$ cells in the pathogenesis of yersinia associated arthritis in the rat remain to be studied.

We thank J Hill, PhD, for help in preparing the manuscript. This work was supported by the Sigrid Jusélius Foundation.

1 Volkman A, Collins F M. Polyarthritis associated with Salmonella infection in rats. Infect Immun 1973; 8: 814-8. 2 Volkman A, Collins F M. Pathogenesis of Salmonellaassociated arthritis in the rat. Infect Immun 1975; 11 222-30.

3 Toivanen A, Merilahti-Palo R, Gripenberg C, LahesmaaRantala R, Söderström K-O, Jaakkola U-M. Yersiniaassociated arthritis in the rat: Experimental model for human reactive arthritis? Acta Pathol Microbiol Immunol Scand Sect [C] 1986; 94: 261-9.

4 Carter P B, Varga C F, Keet E E. New strain of Yersinia enterocolitica pathogenic for rodents. Appl Microbio 1973; 26: 1016-8.

5 Hill J L, Yu D T Y. Development of an experimental animal model for reactive arthritis induced by Yersinia enteromodel for reactive arthritis induced by Yersini

6 Hill J L, Yu D T Y. Role of genetic susceptibility to bacterial infection in reactive arthritis. Arthritis Rheum 1987; 30: 524.

7 Hill J L, Yong Z, Laheji K, Kono D H, Yu D T Y. Experimental animal models of Yersinia infection and Yersinia-induced arthritis. Contrib Microbiol Immunol 1987; 9: $228-32$.

8 Toivanen P, Merilahti-Palo R, Gripenberg C, Söderström K-O, Jaakkola U-M. Experimental Yersinia-associated arthritis in the spontaneously hypertensive rat. $\mathrm{Br} \mathcal{J}$ Rheumatol 1988; 27 Suppl II: 52-4.

9 Laird W J, Cavanaugh D C. Correlation of autoagglutination and virulence of Yersiniae. F Clin Microbiol 1980; 11: 430-2.

10 Koch A L. Growth measurement. In: Gerhardt P, Murray R G E, Costilow R N, et al, eds. Manual on methods for general bacteriology. Washington, DC: American Society for Microbiology, 1981: 188-91.

11 Schiemann D A. Development of a two-step enrichment procedure for recovery of Yersinia enterocolitica from food. Appl Environ Microbiol 1982; 43: 14-27.

12 Cromartie W J, Craddock J G, Schwab J H, Anderle S K, Yang C-H. Arthritis in rats after systemic injection of streptococcal cell walls. F Exp Med 1977; 146: 1585-602.

13 Lahesmaa-Rantala $R$, Toivanen A. Clinical spectrum of reactive arthritis. In: Toivanen $A$, Toivanen $P$, eds. Reactive arthritis. Boca Raton, FL: CRC Press, 1988: 1-13.

14 Cassell $\mathrm{G} H$. The pathogenic potential of mycoplasmas: Mycoplasma pulmonis as a model. Rev Infect Dis 1982; 4: S18-34.

15 Taurog J D, Leary S L, Cremer M A, Mahowald M L, Sandberg G P, Manning P J. Infection with Mycoplasma pulmonis modulates adjuvant- and collagen-induced arthritis in Lewis rats. Arthritis Rhewm 1984; 27: 943-6.

16 Granfors K. Measurement of immunoglobulin M (IgM), IgG and IgA antibodies against Yersinia enterocolitica by enzyme-linked immunosorbent assay: persistence of serum antibodies during disease. $f$ Clin Microbiol 1979; 9: $336-41$.

17 Keat A, Thomas B, Dixey J, Osborn M, Sonnex C, TaylorRobinson D. Chlamydia trachomatis and reactive arthritis: the missing link. Lancet 1987; 1: 72-4.

18 Schumacher H R Jr, Magge S, Cherian P V, et al. Light and electron microscopic studies on the synovial membrane in Reiter's syndrome: immunocytochemical identification of Chlamydial antigen in patients with early disease. Arthritis Rheum 1988; 31: 937-46.

19 Granfors K, Jalkanen S, von Essen R, et al. Yersinia antigens in synovial-fluid cells in reactive arthritis. $N$ Engl f Med 1989; 320: 216-21.

20 Granfors K, Jalkanen S, Lindberg A A, et al. Salmonella lipopolysaccharide in synovial cells from patients with lipopolysaccharide in synovial cells from

21 Merilahti-Palo R, Söderström K-O, Lahesmaa-Rantala $R$, Granfors $K$, Toivanen A. Bacterial antigens in synovial biopsy specimens in yersinia-triggered reactive arthritis. Ann Rheum Dis 1991; 50: 87-90.

22 Viitanen A-M, Arstila T P, Lahesmaa R, Granfors $K$, Skurnik M, Toivanen P. Application of the polymerase chain reaction and immunofluorescence techniques to the detection of bacteria in Yersinia-triggered reactive arthritis. detection of bacteria in Yersinia-trige

23 Arthritis Rheum 1991; 34: 89-96. Merilahti-Palo R, Toivanen A. Heart-reactive antibodies in yersiniosis. International foumal of Immunopathology and Immunopharmacology 1988; 1: 63-7.

24 Toivanen A, Toivanen P. Pathogenesis of reactive arthritis. In: Toivanen A, Toivanen $\mathrm{P}$, eds. Reactive arthritis. Boca Raton, FL: CRC Press, 1988: 167-78.

25 Toivanen A, Granfors K, Lahesmaa-Rantala R, Toivanen P. Immunological and bacteriological aspects of reactive arthritis. Rheumatol Int 1989; 9: 201-3. 